\title{
Análise de protocolos de desobturação de canais radiculares para colocação de pino.
}

O objetivo desta pesquisa foi avaliar protocolos de limpeza de material obturador das paredes do canal radicular e a quantidade de desgaste da dentina radicular em dentes preparados para colocação de pino. O artigo I avaliou-se a limpeza das paredes do canal radicular após diferentes protocolos de remoção de obturação para preparo para pino e preservação de estrutura remanescente; e, no artigo II avaliou-se a resistência de união por meio do teste push out e o tipo de falha predominante em dentes com tratamento endodôntico e reabilitados com pino de fibra de vidro. No artigo I, os grupos foram distribuídos de acordo com os instrumentos e protocolos utilizados na remoção do material obturador: brocas de Gates Glidden, broca de Largo, broca específica do kit de pinos, inserto para ultrassom Clearsonic, inserto Clearsonic + instrumento Easy Clean e Inserto Clearsonic + Irrisonic. Como solução irrigadoras foram utilizados o hipoclorito de sódio a 1\%, água deionizada e EDTA a 17\%, porém, o protocolo de irrigação final foi diferente para os grupos. A avaliação foi realizada em Micro CT e Microscopia eletrônica de Varredura. No artigo II, foi avaliada a resistência de união por meio do teste push out e o tipo de falha predominante observada por meio de microscopia eletrônica de varredura (MEV) com aumento de 25x e por meio do Estereomicroscópio. Os resultados do artigo I - o grupo Clearsonic demonstrou melhor desempenho e promoveu paredes mais limpas. Não houve diferença estatisticamente significante entre os grupos quanto ao desgaste de dentina radicular remanescente. No artigo II, os melhores resultados foram para o grupo do inserto Clearsonic, apresentando maiores valores de resistência de união. O tipo de falha predominante para os dois grupos foi a adesiva na interface entre o cimento e a dentina. Conclusão: os dois artigos mostraram que o inserto Clearsonic foi mais efetivo na remoção de material obturador sem desgaste de dentina remanescente e, promoveu maiores valores de resistência de união em pinos de fibra de vidro cimentados com cimentos autoadesivos.

Palavras-chave: Preparo para pino; Remoção de material obturador; Clearsonic; Irrisonic; Easy Clean; Endodontia. 